20 Breuer AC, Furlan AJ, Hanson MR, et al. Neurologic complications of open heart surgery. Cleve $C$ lin $Q$ 1981;48:205-6.

21 Breuer AC, Furlan AJ, Hanson MR, et al. Central nervous system complications of coronary artery bypass graft surgery: prospective analysis of 421 patients. Stroke 1983;14:682-7.

22 Lederman RJ, Breuer AC, Hanson MR, et al. Peripheral nervous system complications of coronary artery bypass graft surgery. Ann Neurol 1982;12:297-301.

23 Lee MC, Geiger J, Nicoloff D, Klassen AC, Resch JA. Cerebrovascular complications associated with coronary artery bypass (CAB) procedure. Stroke 1979;10:107.

24 Gonzaáles-Scarano F, Hurtig H. Neurologic complications of coronary artery bypass grafting: case-control study. Neurology $(N Y)$ 1981;31:1032-5.

25 Martin WRW, Hashimoto SA. Stroke in coronary bypass surgery. Can f Neurol Sci 1982;9:21-6. 26 Bojar RM, Najafi H, Delaria GA, Serry C, Goldin MD. Neurological complications of coronary revascularisation. Ann Thorac surg 1983;36:427-32.

27 Coffey CE, Massey W, Roberts KB, Curtis S, Jones RH, Pryor DB. Natural history of cerebral complications of coronary artery bypass graft surgery. Neurology 1983;33:1416-21.

28 Sotaniemi KA. Cerebral outcome after extracorporeal circulation. Comparison between prospective and retrospective evaluations. Arch Neurol 1983;40:75-7.

29 Menkin M, Schwartzman RJ. Cerebral air embolism. Report of five cases and review of the literature. Arch Neurol 1977;34:168-70.

30 McKibbon DW, Bulkley BH, Green WR, Gott VL, Hutchins GM. Fatal cerebral atheromatous embolization after cardiopulmonary bypass. 7 Thorac Cardiovasc Surg 1976;71:741-5.

31 Breuer AC, Franco I, Marzewski D, Soto-Velasco J. Left ventricular thrombi seen by ventriculography are a significant risk factor for stroke in open-heart surgery. Ann Neurol 1981;10:103-4.

32 Caguin F, Carter MG. Fat embolism with cardiotomy with use of cardiopulmonary bypass. $\mathcal{f}$ Thorac cardiovasc Surg 1963;46:665-72.
33 Arfel G, Casanova C, Naquet R, Passelecq J, Dubost C. Etude électro-clinique de l'embolie gazeuse cérébrale en chirugie cardiaque. Electroencephalogr Clin Neurophysiol 1967;23:101-6.

34 Guidoin RG, Awad JA, Laperche Y, Morin PJ, Haggis GH. Nature of deposits in a tubular membrane oxygenator after prolonged extracorporeal circulation: a scanning electromicroscopy study. I Thorac Cardiovasc Surg 1975;69:479-91.

35 Hill JD, Aguilar MJ, Baranco A, de Lanerolle P, Gerbode F. Neuropathological manifestations of cardiac surgery. Ann Thorac Surg 1969;7:409-14.

36 Lindberg DAB, Lucas FV, Sheagren J, Malm JR. Silicone embolisation during clinical and experimental heart surgery employing a bubble oxygenator. Am f Pathol 1961;39:129-35.

37 De Paepe J, Pomerantzeff PMA, Nakiri K, Armeline E, Verginelli G, Zerbini EJ. Observation of the microcirculation of the cerebral cortex of dogs subjected to pulsatile and non-pulsatile flow during extracorporeal circulation. In: $A$ propos du debit pulse. Paris: Cobe Laboratories Inc, 1979.

38 Stockard JJ, Bickford RG, Schaube JF. Pressure dependent cerebral ischemia during cardiopulmonary bypass. Neurology (Minneap) 1973;23:521-9.

39 Hansen MR, Breuer AC, Furland AJ, et al. Mechanism and frequency of brachial plexus injury in open-heart surgery: a prospective analysis. Ann Thorac Surg 1983;36:675-9.

40 Vander Salm TJ, Cereda JM, Cutler BS. Brachial plexus injury following median sternotomy. $\mathcal{I}$ Thorac Cardiovasc Surg 1980;80:447-52.

41 Magee KR. Clinical analysis of reflexes. In: Vinken PJ, Bruyn GW, eds. Handbook of clinical neurology. Vol 1. Amsterdam: North Holland Publishing Co, 1969:237-56.

(Accepted 7 August 1985)

\section{Importance of early tumour exacerbation in patients treated with long acting analogues of gonadotrophin releasing hormone for advanced prostatic cancer}

We describe the transient stimulatory effect- "tumour flare"-that occurred in patients with locally advanced or metastatic symptomatic prostatic cancer who were treated with either buserelin (D-ser (TBU) ${ }^{6}$ LHRH ethylamide) or decapeptyl (D-(Trp) $)^{6}$ LHRH), agonist analogues of gonadotrophin releasing hormone.

\section{Patients, methods, and results}

Forty six men aged 52-82 with symptomatic locally advanced or metastatic prostatic cancer were treated. Five patients received buserelin $200 \mu \mathrm{g}$ thrice daily, 17 buserelin $200 \mu \mathrm{g}$ five times daily, and eight buserelin $400 \mu \mathrm{g}$ thrice daily intranasally, and five men were treated with monthly depot injections of buserelin calculated to release the compound at a mean rate of $150 \mu \mathrm{g}$ daily. Eleven patients received depot injections of decapeptyl, which released the drug at a mean rate of 50,100 , or $200 \mu \mathrm{g}$ daily over one month. Treatment was given for between one month and three years. All patients were assessed according to the criteria of the National Prostatic Cancer Project.

Objective improvement occurred in 26 of the 35 patients treated with buserelin and eight of the 11 patients treated with decapeptyl. Seventeen of 32 with bone pain at presentation and one without, however, had increased symptoms. Pain was generally first noted to have increased at 12 hours, became maximal at 36 hours, and eased by the end of the first treatment week. A patient with pelvic lymphadenopathy developed lymphoedema, which resolved after one week of treatment.

The 17 patients with increased bone pain experienced some additional problems. Four had increased lymphoedema, which was maximal at the end of the first treatment week and had resolved at one month. The serum creatinine concentration in one patient increased from 170 to $600 \mu \mathrm{mol} / \mathrm{l}(1.92$ to 6.79 $\mathrm{mg} / 100 \mathrm{ml}$ ) at the eighth treatment day and decreased at the end of the second treatment week.

The most serious case of tumour flare occurred in a patient presenting with bone pain and grade 4 weakness in the legs, who developed signs of compression of the cord with complete sphincter dysfunction and grade 3 weakness on the 13th treatment day. A pretreatment myelogram had shown indentation of the theca at lumbar disc spaces 1-4 while a myelogram on day 13 showed gross compression of the theca between the third and fifth lumbar vertebrae (figure). This patient had spinal radiotherapy and recovered full neurological function. Fourteen of the 19 patients with tumour flare responded to treatment.

\section{Comment}

Agonist analogues of gonadotrophin releasing hormone have provided an appreciable advance in the management of patients with advanced carcinoma of the prostate. ${ }^{1.3}$ They are equivalent in efficacy to conventional treatment for prostatic cancer ${ }^{4}$ but without its disadvantages. Because of the initial stimulatory effects of all agonists analogues, however, there may be a corresponding temporary increase in symptoms. Of the $46 \mathrm{men}$ in this series, 19 had increased symptoms. In two of this group renal and neurological function was severely compromised.

Labrie et al suggested that combined treatment with an antiandrogen and agonist analogues may improve the response and its duration and avoid tumour flare. ${ }^{5}$ We have described the incidence and potential importance of the initial stimulatory effects of agonist analogues. These observations do not minimise the contribution of the gonadotrophin releasing hormone
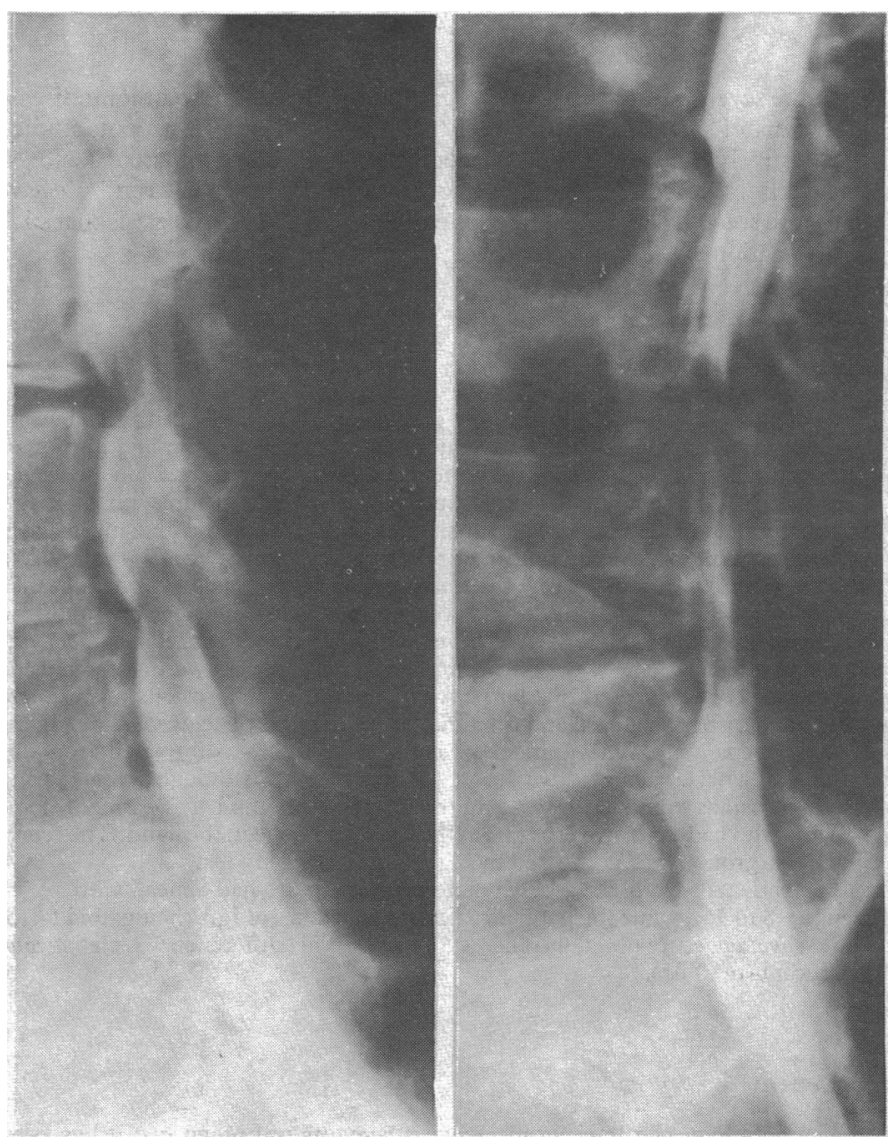

Changes in myelogram in patient with tumour flare in lumbar region. Left: Before treatment. Right: On day 13 of treatment. 
agonists to the management of prostatic cancer but emphasise the importance of further investigation into their combined use with antiandrogens.

We thank Anne Buxton, who helped to compile the data.

1 Tolis G, Ackman D, Stellos A, et al. Tumor growth inhibition in patients with prostatic cance treated with luteinizing hormone releasing hormone agonists. Proc Natl Acad Sci USA 1982;79:1658-62. testosterone production by the luteinizing hormone releasing hormone agonist buserelin in patients with advanced prostatic carcinoma: a new therapeutic approach. Lancet 1982;i:1097-9.

3 Waxman JH, Wass JAH, Hendry WF, et al. Treatment with gonadotrophin releasing hormone analogue in advanced prostatic cancer. Br Med f 1983;286:1309-12.

4 Leuprolide Study Group. Leuprolide versus diethylstilbestrol for metastatic prostatic cancer. $N$ Engl f Med 1984;311:1281-6.

5 Labrie F, Dupont A, Belanger A, et al. New approach in the treatment of prostatic cancer: complete instead of partial withdrawal of androgens. Prostate 1983;4:519-94.

(Accepted 7 August 1985)

St Bartholomew's Hospital, London EC1

JONATHAN WAXMAN, BSC, MRCP, Imperial Cancer Research Fund research fellow and honorary senior registrar (also at Institute of Urology and London Hospital)

A MAN, BMEDSCI, MRCP, Imperial Cancer Research Fund research fellow

W F HENDRY, CHM, FRCS, consultant urologist

H N WHITFIELD, MCHIR, FRCS, consultant urologist

G M BESSER, DSC, FRCP, professor of endocrinology

London Hospital, Whitechapel, London E1

R C TIPTAFT, BSC, FRCs, consultant urologist

A M I PARIS, FRCS, consultant urologist

R T D OLIVER, MD, FRCP, Sir Maxwell Joseph reader in medical oncology (also at

Institute of Urology and St Bartholomew's Hospital)

Correspondence to: Dr Waxman.
2 Borgmann V, Hardt W, Schmidt-Gollwitzer M, Adenauer H, Nagel R. Sustained suppression of seronegative "rheumatoid arthritis": a controlled study. Ann Rheum Dis 1983;42:605-12.

Department of Rheumatology, St Mary's Hospital, Paddington, London W2

Both the severity of radiological progression and the pattern of joint disease in rheumatoid arthritis are extremely variable. In a series of patients studied prospectively those with high concentrations of IgA rheumatoid factor in their serum showed a predominance of erosions affecting the wrist. ' We have therefore studied a larger number of patients to test the hypothesis that such an association exists.

\section{Patients, methods, and results}

We studied 46 patients with definite or classical rheumatoid arthritis. Twenty three had raised values of IgA rheumatoid factor in their serum and in the rest these values were normal. Nineteen patients in the first group and 21 in the second had raised IgM rheumatoid factor concentrations. The group with high IgA rheumatoid factor values consisted of six men and 17 women with a mean age of 56.5 years (range 34-78) and a mean duration of disease of 8.7 years (range 2-24), and the group with normal IgA rheumatoid factor values comprised eight men and 15 women with a mean age of $54 \cdot 6$ years (range $35-74$ ) and a mean duration of disease of $7 \cdot 6$ years (range $2-25$ ). Rheumatoid factor was measured by an enzyme linked immunosorbent assay. ${ }^{2}$ Radiographs of hand and wrist were assessed using the defect score described by Sharpe et al ${ }^{3}$ the scores for erosions in wrist and hand (metacarpophalangeal and proximal and distal interphalangeal joints) being recorded separately. The number of hand erosions was subtracted from the number of wrist erosions to give a score for each patient. Although a ratio of hand to wrist erosions would have been a more satisfactory method of assessment, some patients who had extensive erosions in the wrist had none in the hand. The scores in the two groups were compared by Wilcoxon's rank sum test.

The patients with high IgA rheumatoid factor values had a mean score of $7 \cdot 1$ (range -8 to 36 ), while the patients with normal values of IgA rheumatoid factor had an average score of -0.4 (range -32 to 18 ). This difference was statistically significant $(p<0.05)$.

\section{Comment}

The aetiology of rheumatoid arthritis remains unknown but it has been suggested that the disease may represent several disorders with different immunogenetic backgrounds and environmental trigger factors. This possible heterogeneity makes the search for aetiological factors very difficult. It therefore seems reasonable to look for subgroups of disease and that studying these separately may help elucidate the problem. IgA rheumatoid factor has already been associated with a poor prognosis in rheumatoid arthritis. ${ }^{\prime}$ Finding an association with a particular radiological pattern lends further support to the view that patients with rheumatoid arthritis and high values of IgA rheumatoid factor may represent a subgroup of the disease. This association has been shown despite our patients having established disease, for which several had received "specific" or disease modifying agents (gold salts, penicillamine, steroids) which lower IgA rheumatoid factor values (unpublished observations). Burns and Calin have reported a different radiological pattern in patients with seronegative rheumatoid arthritis. (Some patients who are conventionally seronegative have high values of IgA rheumatoid factor in their serum.) They interpreted their findings as suggesting that seronegative rheumatoid arthritis has a different pathological mechanism from seropositive rheumatoid arthritis. Other studies categorising the radiological progression of rheumatoid arthritis have noted an association between rheumatoid factor titre and severity of erosive disease but have not commented on the pattern of joint erosion. ${ }^{35}$

Though it is unclear why IgA rheumatoid factor should be a marker for a disease subset of rheumatoid arthritis, we believe that IgA rheumatoid factor deserves closer examination in patients with rheumatoid arthritis.

We acknowledge the help of Dr Ingvar Teitsson, who performed the rheumatoid factor assays.

1 Teitsson I, Withrington RH, Seifert MH, Valdimarsson $\mathrm{H}$. Prospective study of early rheumatoid arthritis. 1. Prognostic value of IgA rheumatoid factor. Ann Rheum Dis 1984;43:673-8.

Teitsson I, Valdimarsson $H$. Use of monoclonal antibodies and $F\left(a b^{\prime}\right)_{2}$ enzyme conjugates in ELISA for IgM, IgA and IgG rheumatoid factors. I Immunol Methods 1984;71:149-61.

3 Sharpe JT, Lidsky MD, Collins LC, Moreland J. Methods of scoring the progression of radiological changes in rheumatoid arthritis: correlation of radiological, clinical and laboratory abnormalities. changes in rheumatoid arthritis:

4 Burns TM, Calin A. The hand radiograph as a diagnostic discriminant between seropositive and

5 Masi AT, Maldonado-Cocco JA, Kaplan SB, Feigenbaum SL, Chandler RW. Prospective study of the early course of rheumatoid arthritis in young adults. Comparison of patients with and withou rheumatoid factor positivity at entry and identification of variables correlating with outcome. Semin Arthritis Rheum 1976;5:299.

(Accepted 7 August 1985) ROBIN H WITHRINGTON, MB, MRCP, senior registrar in rheumatology MARTIN H SEIFERT, MB, FRCP, consultant in rheumatology

Correspondence to: Dr Withrington.

\section{The neglected hospital wheelchair}

Hospital wheelchairs are in constant use and have to withstand considerable wear. We observed that many were in a poor state of repair and that patients had sustained injuries owing to faulty wheelchairs. A previous study identified some faults in hospital wheelchairs, ${ }^{1}$ but the prevalence and implications of such faults have not been assessed. We examined this problem.

\section{Methods and results}

We inspected all the transit and self propelled wheelchairs in a geriatric hospital ( 215 beds) and all those in the medical wing of a teaching hospital ( 204 beds). The type of tyre (pneumatic or solid) was recorded, and the backrest, seat, armrests and footrest plates were examined for defects. The pneumatic tyres were inspected for wear and state of inflation. They were recorded as worn if the central part of the tread was indistinct, soft if there was insufficient air to support a person sitting in the wheelchair and excessive bulging of the tyre occurred, and deflated if there was clearly no air in the inner tube. The deflated tyres were pumped up, their valves tested, and the tyres later re-examined to determine if a puncture was present. Steering and brakes were tested with a person sitting in the wheelchair. Each brake was applied separately and recorded as defective if the wheelchair could still be moved easily.

To evaluate injuries to patients caused by defective wheelchairs we prospectively investigated for two months all accidents on our geriatric unit in which wheelchairs played a part and that required the completion of a hospital accident report.

There were 93 wheelchairs in the geriatric hospital and 30 in the medical wing Only 21 and seven, respectively, were free from faults. The table gives details of the faults found. Wheelchair arms were termed dangerous when their foam covering had been torn away, exposing the sharp ends of the bolts inside. Spikes on the footrest plates were sharp vertical projections that remained on the 